\title{
Louise Fabian
}

\section{Stedets identitet til genforhandling - London som postimperial metropol}

De relationer mellem magt, rum og etablering af forskelle og forbindelser, der blev etableret i løbet af imperialismen, bliver på forskellig vis stadig opretholdt og genforhandlet i nutidens metropoler. Nærværende artikel vil vise, hvorledes nutidens forvaltning og transformation af Londons byrum genforhandler, genfortolker og til tider reproducerer de relationer mellem magt, sted og identitet, der har spor tilbage til imperiets tid, samtidig med at London forsøger at redefinere sig selv på globaliseringens præmisser. Artiklens første teoretiske del vil introducere og træde i dialog med udvalgte stedteorier, der i forlængelse af globaliseringsdebatten har bidraget til at udvikle et begreb om stedet som værende en åben, porøs, processuel hybrid. Artiklens anden analytiske del vil afprøve det fremlæste hybride stedsbegreb i en udforskning af, hvorledes kampen om retten til at udlægge og forvalte stedet og dets fortid, nutid og fremtid udspilles i Londons East End

I løbet af de sidste 20-30 år har man inden for human- og samfundsvidenskaberne kunne registrere at begreber som sted, rum, region, landskab, situerethed og lokalisering spiller en stadig mere central rolle i et stadigt bredere felt af discipliner og forskningsområder. ${ }^{1}$ (Soja 1989; Bachmann-Medick 2006; Urry 1995; Döring og Thielmann 2008) Navngivningen og identificeringen af dette såkaldte Spatial Turn kan dateres tilbage til Edward Sojas Postmodern Geographies - the Reassertian of Space in Critical Social Theory fra 1989. Sojas eget ærinde er at "spatialisere den historiske narration" og genindsætte et kritisk spatialt perspektiv i den sociale teori og analyse (Soja 1989: 1). Soja peger på Henri Lefebvre, i særlig grad dennes La production de l'espace (1974), og Michel Foucault som de væsentligste banebrydere for overvindelsen af den vestlige tænknings rumforglemmelse. 
Sojas teori om rummets hidtidige underbelysning understøttes af Edward S. Casey, der i værkerne The Fate of Place - a Philosophical History (1998) og Getting Back into Place - Toward a Renewed Understanding of the Place-World (1993) har forsøgt at råde bod på, hvad han har diagnosticeret som de sidste 200 års 'temporocentrisme' og tro på tidens hegemoni. Casey er mere optaget af begrebet place end space, men argumentationen minder om Sojas. Stedets filosofiske betydning er i filosofien, ifølge Casey, blevet underprioriteret og underordnet begrebet tid. Man har siden oplysningstiden været optaget af udvikling og fremskridt og primært forbundet dette med den tidslige dimension. Den cementerede opdeling af tid og rum og automatiske associering af forandring med tid og stasis med rum er ifølge Casey problematisk. Tid og rum er tæt forbundne, og produktionen af historie er også spatial.

I lighed med Soja begyndte en række humangeografer i løbet af 1980'erne og 1990’erne at kritisere og stille spørgsmål ved forsøgene på at praktisere, hvad der ifølge deres forståelse var en essentialistisk teori om stedet. Disse geografer var inspireret af marxisme, feminisme, post-kolonialisme og poststrukturalisme. Denne nye gren af kulturgeografien annoncerede - inspireret af blandt andre Raymond Williams og Henri Lefebvre - et nyt ægteskab mellem geografien og den kritiske teori. Den kritiske humangeografi afsøger en mængde af måder, hvorpå sted, mening, sociale hierarkier og magt er forbundne. Dette sker eksempelvis ved at udforske, hvorledes identifikation af stedet er involveret i mekanismer, der tjener det formål at inkludere eller ekskludere forskellige befolkningsgrupper og/eller måder at agere på. En række af disse nyfortolkere af stedets betydning såsom Doreen Massey og Edward Soja er fælles om at mene, at stedet ikke er en fikseret ting med en stabil essens, men derimod noget dynamisk, der er i aktion i forhold til noget andet (Massey 1997; Soja 1989). Et paradigmatisk eksempel på en sådan type af læsning er Doreen Masseys A global Sence of Place (1997), hvor hun argumenterer for en ny konception af stedet som værende hybrid, åben og porøs. Steder har ikke rødder men ruter er kongstanken i Masseys tilgang.

Doreen Massey pointerer den sociale og politiske betydning af måderne, hvorpå vi konceptualiserer begreberne space og place, og skriver i eksplicit opposition til forsøg på at formulere, hvad hun anser for at være statiske, eksklusive og essentialistiske definitioner af stedet:

Since the late 1980s the world has seen the recrudescence of exclusivist claims to place - nationalist, regionalist and localist. All of them have been attempts to fix the meaning of particular spaces, to enclose them, endow them fixed identities and to claim them for one's own. Within the academic literature as well as more widely there has been a continuation of the tendency to identify 'places' as 
nessesarily sites of nostalgia. [...] It is a view of place as bounded, as in various ways a site of authenticity, as singular, fixed and unproblematic in its identity. It is a conceptualization of place which rests in part on the view of space as stasis. (Massey 1994: 4-5)

Som alternativ til et statisk begreb om stedet vil Massey sætte et syn på stedet som værende en artikulation af de netværk af sociale relationer, der konstituerer det spatiale. Stedet defineres ikke udelukkende internt inden for en afgrænset horisont, men konstitueres også gennem forbindelser til det, der ligger uden for stedet.

Den interdisciplinære rekonceptualisering af begreberne sted og rum taler ind i en samfundsmæssig kontekst præget af en række transformationer afledt af globaliseringen. Globaliseringen er kendetegnet ved en stadig større udstrækning af det rum, individet kan agere, kommunikere og etablere relationer i (Giddens 1990; Tomlinson 1999). Denne horisontalisering af den menneskelige tilværelse (Nielsen 2005: 17) har bidraget til den fornyede interesse for rum og steder og for forholdet mellem det globale og det lokale. I takt med at succesfulde multinationale selskaber, diverse mediefællesskaber og internationale modefænomener indenfor tøj-, mad- og drikkevaner spredtes til store dele af verden, begyndte den tidlige globaliseringsdiskussion at registrere tegn på en tiltagende forskelsløshed fra sted til sted, hvilket fristede flere teoretikere til den antagelse, at geografisk lokalisering i dag spiller en stadig mindre rolle. Edward Relph i Place and Placelesness (1976) og Marc Auge i Non-places - Introduction to an anthropology of supermodernity (1995) advarede eksempelvis mod, hvad de diagnosticerede som tiltagende "stedsløshed".

I dag mener de fleste imidlertid, at globaliseringen har medført komplekse hybrider snarere end en fælles homogen standard (Short 2006: 62; Tomlinson 1999; Pietersee 1995; Robertson 1995). Globaliseringen går hånd i hånd med en fornyet opmærksomhed på det lokale partikulære (Nederveen Pieterse 1995; Robertson 1995). Globale processer bidrager på forskellig vis til restrukturering af det lokale og kan genere såvel fragmentering som bevidsthed om fællesskab. Nederveen Pietersee søger i opposition til Giddens at udvikle en globaliseringsteori, der undgår at forstå globalisering som en proces drevet af vestlige moderniseringsprocesser, men derimod som en proces kendetegnet ved en pluralisering af organisationsformerne, der skaber nye strukturelle hybrider. $^{2}$

Hybridens rum er ifølge den postkoloniale teoretiker Homi K. Bhaba det rum, hvor kulturen altid bærer spor af andre betydninger og identiteter. Bhaba er inspireret af Fredric Jamesons Postmodernism Or, The Cultural Logic of Late Capitalism, og den postmodernistiske teori og postkoloniale teori er netop 
fælles om at forsøge at dekonstruere masterfortællinger, rokke ved binære oppositioner og tillade marginaliserede erfaringer at komme til orde. ${ }^{3}$ Som Edward Soja forsøger Bhaba at udvikle en geografisk teori, der ikke tænker i binære oppositioner men i "in-between spaces". ${ }^{4}$ Det postmoderne menneske er ifølge Jameson og Bhaba ud af stand til at kortlægge de decentrerede multinationale netværk af informationer, varer, kapitel og mennesker, der kendetegner det inkommensurable globale rum præget af nye transnationale hybrider. (Bhaba 1994: 2)

Edward Saids mantra "Nations are narrations" har domineret de sidste årtiers nationalitetsforskning. Men ikke kun nationer er fortalte. Steder er ligeledes fortalte, socialt konstruerede og praktiserede. London vrimler med koloniale og postkoloniale spor af produktion og reproduktion af identitet. Edward Saids Culture and Imperialism, hvor tesen som nations som narrations udfoldes, omhandler det 19. og 20. århundredes vestlige imperialisme. Said vier en stor del af sin opmærksomhed til skriftlige vidnesbyrd, i særlig grad romanen, som han anser for at være en privilegeret kilde og for at have en central rolle i dannelsen af imperiale attituder, referencer og erfaringer. De imperiale betydningsdannelser er imidlertid ikke kun at finde i skriftlige kilder samt i diverse fortællinger og forestillinger, men også i forskellige former for materialitet såsom populærkultur, arkitektur, museumspraksiser, byplanlægninger, parker, mindesmærker mv.

Said analyserer, hvilken rolle forbindelsen mellem konstrueret kollektiv erindring og forestillede geografier spiller i erobringen og domineringen af territorier, og hævder i sine udforskninger af imperialismens kulturelle dimensioner, at steders forestillede geografier kan manipuleres, opfindes og karakteriseres mere eller mindre uafhængigt af lokaliteters fysiske realiteter. Hvor Said primært beskæftiger sig med, hvorledes den vestlige verden gør mennesker og steder uden for den vestlige verden til den store Anden, så vil nærværende artikel se på, hvad der sker med forvaltningen af byrummet $i$ den vestlige metropol, når det koloniale projekts Anden flytter til den vestlige metropol. Inspireret af Jane Jacobs Edge of Empire - postcolonialism and the city, hvor hun viser, hvorledes det postmoderne byrum inkorporerer og opretholder imperiale og postkoloniale geografier, vil jeg i nærværende artikel søge de koloniale og postkoloniale spor ikke i de imaginære geografiers skriftlige udtryk men i den gamle metropols nuværende materielle fremtrædelse. Artiklens ærinde er altså ikke at se på den imaginære geografi mere eller mindre løsrevet fra den faktiske materialitet, men snarere netop at udforske sammenhængen mellem forestillinger, repræsentation, praksis og materialitet.

At samle, at vidne, at bevidne, at indrømme og at undskylde. Alle disse gesti har været involveret $\mathrm{i}$ forvaltningen og konstruktionen af steder og steders 
arv. Forvaltningen af steder, der er ladet med kulturarv rejser en række spørgsmål om, hvordan vi knytter steder til erindringer og om, hvordan magt er involveret i forvaltningen og forståelsen af historie, geografi og kulturarv.

I Londons ser vi adskillige eksempler på overleverede praksisformer og materialitet, der afspejler et ønske om at samle og udstille imperiet i dets moderskød såsom Kew Garden, Victoria \& Albert Museum, Albert Memorial, Natural History Museum og British Museum. ${ }^{5}$ Institutioner som Victoria and Albert Museum og Kew Gardens materialiserede og manifesterede den herskende imperiale magt. Briternes længe herostratisk berømmede evne til at indsamle og katalogisere diverse objekter fra diverse civilisationer bevidnes $\mathrm{i}$ disse institutioner.

I det 19. århundrede begyndte museerne at forvandle sig fra at være semiprivate institutioner primært for de herskende klasser til at blive dedikeret til oplysning og uddannelse af den bredere offentlighed. (Bennett 1995: 109) Victoria and Albert Museum blev grundlagt i 1852 og officielt åbnet på sin nuværende placering af dronning Victoria den 22. juni 1857. Fra og med 1858 muliggjorde gasbelysning, at museet kunne holde aftenåbent med det erklærede mål at gøre museet tilgængeligt for de arbejdende klasser, og dermed tjene statens moralske opdragende funktion. Museet, hvis oprindelige navn var The Museum of Artefacts, havde sit udspring i The Great Exhibition i 1851, og skulle fortsat understøtte industrien. Men Viktoriatidens filantropi var flertydig. Flere aristokratiske konnotationer arvedes fra de tidligere samlingers karakter af at være testamente over deres samleres storhed, og disse kulturens og civilisationens templer var i praksis ofte udformet lige så meget med henblik på at overvælde og imponere som på at informere (Bennett 1995:118). Flere af disse institutioner og bygninger står tilbage i Londons bybillede i dag, og er en del af de former, gennem hvilke en stor del af nutidens indbyggere og besøgende tilegner sig Londons byrum, og de forestillinger, ideer og fortællinger byrummet inkorporerer. Fortiden er present i nutidens materialitet. Men fortiden er polyfon. Der er altid flere fortider og følgelig ofte stridigheder om, hvilke der skal fortælles videre på.

\section{The biggest and greatest town on Earth}

The Nellie, a cruising yawl, swung to her anchor without a flutter of the sail, and was at rest. The flood had made, the wind was nearly calm, and being bound down the river, the only thing for it was to come to and wait for the turn of the tide. [...] The sea-reach of the Thames stretched before us like the beginning of an interminable waterway. The air was dark above Gravesend, and farther back 
still seemed condensed into a mournful gloom, brooding motionless over the biggest, and the greatest, town on earth. [...] The old river in its broad reach rested unruffled at the decline of day, after ages of good service done to the race that peopled its bank, spread out in the tranquil dignity of a waterway leading to the uttermost ends of the earth. (Conrad 1994: 5-6)

Ovenstående indledning til Joseph Conrads Heart of Darkness (1899) tegner et billede af det koloniale ordningssystem, hvor Themsen udgør forbindelseslinjen, der muliggør bevægelsen mellem de to koloniale topoi: Den imperialistiske metropol "The biggest and greatest town on Earth"(Conrad 1994:5) og kolonierne. ${ }^{6}$ Themsen spiller en vigtig rolle i den engelske nationalforståelse som identitetsgivende national flod, der løber gennem Englands historie, kunst, litteratur og musik. Londons placering ved Themsen bestemte Romerne grundlæggelse af det daværende Londoniums centrale status, da romerne benyttede sig af Londons placering til at gøre den til centrum for import og eksport af varer til det romerske imperiums udsendte soldater, administratorer, handelsmænd og hvad dertil hørte. Da Joseph Conrad i 1878 trådte ind i den britiske handelsflåde og rejste til Singapore, Australien, Belgisk Congo, Bombay og Ostindien var rollerne byttet om. Da var det ikke længere Rom, der var imperiets centrum og London den fugtige, tågede udpost. Men derimod London, der var imperiets centrum og moderskød.

Dokkerne var på Conrads tid en væsentlig del af den imperiale økonomi, varer fra alle imperiets hjørner blev bragt til London og opbevaret i dokkerne. Allerede fra 1700-tallet begyndte byens og handelslivets vækst at fordre yderligere havnekapacitet. Navnene på dokkerne taler deres eget tydelige sprog om sammenhængen mellem Londons havneområde og imperiet. I $1802 \mathrm{blev}$ West India Dock indviet, i 1805 fulgte London Dock, i 1806 East India Dock og i 1812 Regent's Canal Dock. Såvel London som imperiet ekspanderede og i 1828 færdiggjordes Thomas Telfords St. Kathrine's Dock. Også i Victorias regeringstid (1837-1901) var man vidne til opkomsten af nye Dockområder såsom Poplar Dock (1852), Royal Victoria Dock (1855), Millwall Dock (1868), South West India Dock (1870) og Royal Albert Dock (1880). Det var ikke blot nationale varer som kul, korn, træ og uld, der blev læsset og losset i Londons dokker. Diverse eksotiske varer hjembragt fra kolonierne såsom sukker, kaffe, krydderier, spiritus m.v. blev opbevaret rundt omkring $\mathrm{i}$ de mange pakhuse, og i løbet af 1800-tallet udvikledes i områderne omkring pakhusene en række industrielle aktiviteter såsom skibsværfter og fødevare-, metal- og maskinindustri.

Dokkerne begyndte at opleve nedgangstider allerede inden 2. Verdenskrig, men Blizkrigen og bombningerne af London i 2. Verdenskrig var usædvanlig 
hårde ved Londons dokker, da tyskerne bevidst forsøgte at bombe Englands handelsnerve. Trods en midlertidig delvis genopbygning efter krigen bidrog en række strukturelle og teknologiske ændringer til at undergrave Doklands status som centrum i det engelske handelsimperium. Flere tidligere handelspartnere udviklede egen produktionsindustri og fandt nye handelspartnere. Nye havne ved kysten som Felixstowe, med bedre tilgængelighed for de nyere og større skibe, og kontinentale havne som Rotterdam, med nyere mekaniserede dokker, blev hårde konkurrenter til London. Containerne revolutionerede yderligere arbejdet på dokkerne og i havnene, da de i stor grad overflødiggør opmagasinering i pakhuse, idet de medbringer deres egen beskyttelse, og derfor kan opbevares på store havneområder, hvorefter de transporteres med tog eller lastbil til andre udpakningssteder.

I slutningen af 1960'erne begyndte stadig flere skibe og jobs at forsvinde og flere dokker at lukke ned. En del af dem - begyndende med St Kathrine's Docks - blev omdannet til boliger og kontorer. Forvaltningen af dokområderne i Londons East End blev vigtigt politisk tema. Michael Hesseltine, der var miljøminister under Margaret Thatcher, etablerede i 1981 London Docklands Development Coorporation (LDDC). LDDC havde mandat til at underkende lokale styringer og interesser i et område, der strakte sig 8 mil ned af floden fra Tower Bridge. Opkøbet af de forfaldne og tomme dokker var finansieret af offentlige midler, men havde som erklæret mål at styrke private foretagender og investeringer i området. Da Thatcher midlertidigt protesterede over den centralistiske styrelse, kunne Hesseltine overbevise hende bl.a. ved at henvise til at LDDC ville svække lokale Labour-dominerede autoriteter. Thatcher og Hesseltine var ydermere enige om det afgørende mål; at tiltrække international investering og kapital. (Schneer 2005: 268-269; Toulouse 1991)

London har forsøgt at redefinere sig selv og sin koloniale historie blandt andet ved at fastholde byen som et af verdens vigtigste finanscentre, og det har sat sit præg på byens fysiske fremtoning. Sanerings- og byggeplaner er aktiviteter, der typisk artikulerer såvel sociale som økonomiske visioner. Byplanlægning handler ikke kun om manipulation af de fysiske omgivelser, men lige så meget om bevist brug af tegn og symboler. Projektet med at forny dokkerne og opbygningen af finanscentret Canary Wharf midt på the Isle of Dogs afspejler et politisk og økonomisk ønske om at stadfæste Londons status som internationalt centrum for økonomisk forvaltning, handelsvirksomhed og konsulentvirksomhed, blandt andet ved at flytte en del af Citys aktiviteter mod øst. En af gevinsterne ved at lade finansforetagender og dermed forbundne byggeplaner ekspandere østpå var, at man der kunne tage sig langt større arkitektoniske friheder, der ikke truede det stærkt valoriserede og fredede Citys historiske karakter. 


\section{Imperienostalgi og globaliseringsvisioner}

Imperialistiske forestillinger genaktiveres jævnligt i nutidens Storbritannien eksempelvis med nostalgiske forsøg på at generindre en tabt britisk imperial storhed. Jane Jacobs har dokumenteret, hvorledes konservative og imperienostalgiske røster har været med til at forme arkitekturdebatten i modstanden mod forslag til nybygninger på Bank Junction i City of London:

In the controversy over the development of Bank Junction, the townscape assessments of the development site and its surrounds elaborated the status of this place as the symbolic heart of empire. [...] (T)he assessments of townscape in this 1980s planning struggle express a domesticated memory of empire constructed in opposition to a demonised European other (Jacobs 1996: 41).

City of London blev i 1980'erne midtpunkt i en urban design bevægelse, der advokerede for en forpligtelse overfor et nationalt arkitektonisk formsprog. ${ }^{7}$ Prins Charles er som bekendt en ivrig aktør i den offentlige engelske arkitekturdebat og en skarp kritiker af den megen postmoderne arkitektur, der er skudt op i Londons byrum. Han opponerede mod Cessar Pellis planer for kontorkomplekset Canary Wharf Tower midt på the Isle of Dog, der i dag er Storbritanniens højeste bygning. Flere kritikere har i tråd med Prince Charles arkitekturkritik opfattet Chanary Wharf som et amerikaniseret bylandskabs mord på flere hundrede års historie. Canary Wharfs første byggefase omkring Cabot Square på Canary Warf var da også stærkt præget af Nordamerikanske investorers visioner. Canary Wharfs succes skyldes ikke mindst den forbedrede infrastruktur vha. udvidelsen af Jubilee Line og skabelsen af Docklands Light Railway. Trods succesen kritiseres projektet dog stadig for dets manglende integration $i$ de omgivende bydele, og for at være et kunstigt monotont kapitalistisk produkt, der hult prætenderer at være "lively and vibrant"(Allison 2006: 163-164). Flere kritikere angriber desuden, at metropoler udvikler et skræmmende ens arkitektonisk formsprog, når de vil stadfæstes som global citys (Klingmann 2007: 266).

Nutidens Doklands er dog langt mere end gigantiske sjælløse high-tech kontorbygninger. Det vrimler med kreative og nytænkende arkitektoniske løsninger og miljøer, der bevidst integrerer og konnoterer områdets historie, eksempelvis Container City, hvor gamle containere er stablet og tilført vinduer, døre og balkoner. Med til det postindustrielle landskabs transformationer hører, at flere af dokkerne og pakhusene har undergået en oplevelsesøkonomisk forvandling. Kulturen spiller en vital rolle i nutidens strategiske forvaltning af byernes liv. Kulturøkonomien kommer ofte ind, når den ikke længere rentable industri går ud, og den såkaldt kreative klasse er da også i rigt mål rykket ind 
East End ikke mindst på South Bank med værksteder, cafeer, diverse kulturinstitutioner og boliger. Tate Moderns samlinger for moderne kunst er rykket ind i det tidligere kraftværk på South Bank, og den 35 meter høje og 152 meter lange tidligere turbinehal er forvandlet til en gigantisk katedral for den moderne kunst, mens det enorme pariserhjul London Eye lidt længere oppe af flodbredden er placeret lige overfor og ragende op over både Westminster og Parlamentet. Flere af disse transformationer, kreative forvaltninger og genbrug af den industrielle kulturarv er særdeles vellykkede. Tate Modern bliver med rette ofte fremhævet, men også andre projekter som eksempelvis The Wrapping Project ved Shadwell Bassin, hvor en gammel hydraulisk pumpestation er konverteret til restaurant og kunstgalleri og på forunderlig vis danner rammen om mødet mellem gamle konstruktioner og postmoderne design, fortjener opmærksomhed.

Fra at have været stærkt præget af en konservativ arkitekturdebat har Londonerne siden årtusindskiftet i stigende grad taget den nye eksperimenterende arkitektur til sig. Norman Fosters 41 etagers høje læbestiftsformede kontorbygning til forsikringsselskabet Swiss Re - også kendt som 'the gherkin' - udråbes ofte til at være en af de milepæle, der bidrog til at vende stemningen. London er blevet en af de førende hovedstæder inden for såvel design som arkitektur. En række af verdens førende arkitekter og designere arbejder nu i og fra London. Richard Rogers og Norman Foster har - ikke mindst grundet Labourborgmesteren Ken Livingstones velvilje - sat afgørende præg på bybilledet, men også næste generations arkitekter som Zaha Hadid, Will Alsop og David Chipperfield er brudt igennem. (Sudjic 2004; Powell 2007)

\section{Striden om retten til at udlagge stedet}

Forvaltning af byrummet og den materielle kulturarv har vidtrækkende politiske og identitetsgivende implikationer. Dokkerne var i århundreder hjem og arbejdsplads for massevis af arbejdere, der kæmpede for deres egen og deres familiers overlevelse på meget barske vilkår. Livet på dokkerene var præget af hårdt, dårlig lønnet og farligt arbejde med skiftende uforudsigelige arbejdstider. Dokarbejderne kæmpede for deres rettigheder og vilkår ved at opbygge solidariske fagforeninger, og i 1889 bidrog en omfattende og succesfuld strejke blandt de uuddannede havnearbejdere, med demonstrationer i gaderne i East End, til at inspirere en national organisering af arbejderne samt dannelsen af det socialistiske Independent Labour Party i 1893 og Labour Party i 1900 (Schneer 2006: 168; Howie 1988). Arbejderne i dokkerne har en omfattende og væsentlig historie, der stadig aktiveres som identitetsgivende i diskussionen omkring saneringen af East End, ikke mindst i diskussionen af lokale 
beboeres og autoriteters muligheder for at være med til at forvalte saneringen af området. Det ses eksempelvis tydeligt i flere af artiklerne i Dockland An illustrated historical survey of life and work in east London, der blev udgivet af North East London Polytechnic i samarbejde med the Greater London Council i 1986. I forordet lyder det eksempelvis:

Anyone who regards as a success story the systematic attacks by the LDDC on local and strategic planning, and on local accountability, the confiscation of practically all the housing land in the Dockland part of Newham, Southwark and Tower Hamlets, the loss of thousands of jobs traditional to the area, the madcap schemes for an airport, luxury housing, and huge office developments, cannot be said to have the interests of the residents of Docklands at heart. (Nicholsen 1988: 8)

Saneringen af dokkerne har rejst stedsbundne kampe mellem forskellige koalitioners ønske om at forvalte, udlægge, præge og definere stedets identitet. Striden om retten til at udlægge stedet føres af historikere, lokale politikere, beboere, arbejdere og immigrantgrupper som en kamp om at forvalte historiens rum og konstituere, befæste eller forvalte et tilhørsforhold til stedet. Diskussionerne omkring saneringen af Docklands aktiverer og afspejler konflikter mellem politiske og økonomiske interesser i at redefinere stedet som finanscentrum og forskellige lokale grupperinger og aktører, der mener, at deres historiske eller lokalt forankrede tilknytning til stedet giver dem en særlig ret til at fastholde en bestemt identifikation af stedet og dets transformationer.

\section{Kreativ tilegnelse}

Byer har altid levet af at være centre for immigration. Den formelle dekolonisering og efterkrigstidens migrationer fra de tidligere kolonier til Storbritannien - og her hovedsageligt London - har sat sit præg på Londons demografi og gadebillede. Migrationens bevægelser følger for en stor dels vedkommende en logik, der er struktureret omkring magt- og arbejdsrelationer med spor tilbage til kolonitiden. (Jacobs 1996: 17) Disse strukturer og forestillinger er med til at regulere immigranternes færden samt vedligeholde konstruktioner af identitet og forskel. East End har - på trods af at det tilbagevendende er blevet stærkt brandet som et hvidt arbejderkvarter ${ }^{8}$ - modtaget adskillige strømme af immigranter: irer, russiske og østeuropæiske jøder, italienere, kinesere, indere etc. Da det koloniale projekts Anden for alvor flyttede ind i det tidligere imperiums hjerte, reagerede højreorienterede nationalister som Enoch Powel med at lancere en slet skjult racistisk fortælling om, at den engelske nation måtte reorientere sig og bygge på en forestilling om indfødt og ren Englishness (Ja- 
cobs 1996: 71) Den neo-liberale forvaltning af den globale by er kendetegnet ved stigende social og spatial polarisering (Saskia Sassen 2001; J. R. Short 2006) og ifølge flere kritikere var det en bevidst del af thatcherismens visioner for London og Docklands at svække Labour ved at propagandere for en øget kløft mellem den traditionelle hvide arbejderklasse og de nye underklasser, blandt andet forvaltet ved hjælp af en diskriminerende boligpolitik (Toulouse 1991; Eade and Garbin 2002).

I området Spitalfields omkring Brick Lane, der er domineret af bengalere, har dele af det bengalske samfund forsøgt at kæmpe for deres ret til at identificere stedet og skabe og fastholde bo- og arbejdsmuligheder. Området har været præget af store uroligheder og problemer med racisme. Inspireret af de mange Chinatowns rundt omkring i verden har dele af det bengalske samfund lanceret betegnelsen Banglatown, og dermed gjort immigranternes ophav til en salgbar vare i et multikulturelt samfund, præget af indbyggeres og turisters forbrug af ikke bare varer men også kulturer (Urry 1995). Banglatowns egen hjemmeside udgør et typisk eksempel på, hvorledes nye grupperinger anvender den nye informations- og kommunikations teknologi til at manifestere det lokale - her Banglatown - i det globale. Eksempelvis findes her blandt chatsider og opskrifter en hybrid udgave af netdating, hvor bengalere fra hovedsageligt Storbritannien, Bangladesh og USA annoncerer efter "honorable and religious son in low". Globaliseringsdiskussionen har bl.a. været præget af diskussionen om, hvorvidt den globale billedstrøm, der igennem globale medier spredes til store dele af verden, har en stigende homogenisering til følge. Eksemplet Banglatown viser, at forbruget af kultur og medier ikke blot er en passiv indoktrineringsproces, men at mennesker er aktive og kreative $i$ deres tilegnelse og brug af kultur og medier. Praktiseringen og brandingen af Banglatown viser, hvorledes det lokale konstrueres på baggrund af, hvad Roland Robertson har benævnt "trans- eller super-lokal basis" (Robertson 1995: 26). Lokale territorier genfortolkes som hybride hjem ved hjælp af transnationale netværk og medierede transnationale forestillede fællesskaber. Men de hybride third spaces, der celebreres af postkoloniale teoretikere, er ikke altid lige emancipatoriske (Eade and Garbin 2002). Det bengalske samfund i London er et komplekst samfund med alt fra sekulære grupperinger og tiltag som the Shadinatha Trust, hvis mål er at formidle bengali historie og kulturarv, over synkretistiske muslimske grupper til islamistiske grupperinger tilknyttet East London Mosque. Det bengalske samfund i London er på mange måder tæt forbundet med politiske udviklinger geografisk fjernt fra London. ${ }^{9}$

London vedbliver at være polyfont. Og den formelle dekolonisering og efterkrigstidens migrationer har bidraget yderligere til denne polyfoni. Mennesker approprierer steder og reproducerer, genforhandler eller destabiliserer 
imperiale strukturer gennem aktive handlinger på steder. East End tilegnes og skabes af de forretningsmænd, der indtager deres sandwich blandt de andre sortklædte på bænkene rundt om det computerstyrede springvand på Cabot Square ved foden af Canary Wharf Tower, af den underbetalte rengøringskone fra en af de tidligere kolonier, der gør rent i førnævntes kontorer, af efterkommerne af immigranter fra Bangladesh, der sælger sarier og karryduftende retter i Brick Lane, af indiske Bhajju Shyam, der med en postkolonial gestus og ironisk kommentar til Kipling skriver og maler sin sofistikerede og fortryllede The London Jungle Book, i hvilken London er blevet til den fortyllede, eksotiserede forestillede destination.

Steder tilegnes, fortolkes og etableres gennem handlinger, medieringer og forestillinger. Imperialismen lever videre i såvel nye former for udnyttelse og dominering som i diverse repræsentationer og medieringer, og i oplevelsesøkonomien transformeres den eksotiske erotiserede Anden og det multikulturelle byrum til en vare. Immigranterne forsøges domesticeret, reguleret og kontrolleret. Men som eksemplet Banglatown viser, så træder 'de koloniserede' ikke blot passivt ind i disse konstruktioner af identitet, men kan gå aktivt tilegnende og markedsførende ind og opfinde, genforhandle eller optage disse identifikationer.

\section{Noter}

1 "Space is everywhere of modern thought. It is the flesh that flatters the bones of theory. It is an all-purpose nostrum to be applied whenever things look sticky. It is an invocation which suggests that the writer is right on without her having to give too much away. It is flexibility as explanation: a term ready and waiting in the wings to perform that song-an-dance act one more time." (Crang and Thrift 2000: 1)

${ }^{2}$ Nederveen Pieterse har som en række postkoloniale teoretikere en forkærlighed for begrebet hybrid. Betegnelsen hybrid anvendes indenfor biologien til at benævne dyr eller planter opstået ved en krydsning af forskellige arter. Betegnelsen hybrid anvendes også om ord, hvis dele har etymologiske rødder i forskellige sprog. Hybridisering kan komme til udtryk indenfor mange former: lingvistiske (f.eks. pidgin, kreolsprog) kulturelle, politiske, biologiske etc. Kulturanalysen kan rekurrere på begrebet hybrid ved at læse hybride former og identiteter frem i de urbane erfaringer og kulturelle udtryk.

${ }^{3}$ I Heart of Dakness beskriver Marlow erfaringen af mødet med Congos floddelta som et møde med det, der modstår enhver beskrivelse og fortolkning. I 1994 vender Homi K. Bhaba i The Location of Culture tilbage til Conrad, når han skal beskrive den postmoderne udfordring om at udføre en global kulturanalyse: "The 
Horror! The Horror! Almost a century after Heart of Darkness we have returned to the act of living in the midst of the 'incomprehensible', that Conrad associated with the production of the transcultural narratives in the colonial world." (Bhaba 1994: 216)

${ }^{4}$ Kulturernes globale aspekter og rækkevidde må ifølge Bhaba søges udforsket i følgende typer af kartografier: "What must be mapped as a new international space of discontinuous historical realities in, in fact, the problem of signifying the interstitial passages and processes of cultural difference that are inscribed in the 'in-between', in the temporal break-up that weaves the 'global' text." (Bhaba 1994: 217)

${ }^{5}$ British Museum blev grundlagt i 1753 for en stor del baseret på den private indsamler Sir Hans Sloanes samlinger. Flere private bog- og genstandsamlinger stødte til og fra 1778 tilføjedes stadig flere objekter bragt hjem fra Sydhavet af bl.a. James Cook. I det tidlige 1900 århundrede begyndte de globale indsamlinger fra bl.a. Egypten, Grækenland, Italien, Mellemøsten etc. for alvor at tage fart.

${ }^{6}$ Marlow fortæller til en gruppe europæere, der sidder i mørket på dækket af skibet Nellie, der ligger opankret på Themsen, om sin rejse op af en ganske anden flod, nemlig rejsen i Congo op af floden mod mørkets hjerte "the farthest point of navigation and the culminating point of my experience". Vi hører som læsere hans stemme, som sad vi på dækket med de øvrige europæere omgivet af mørket.

${ }^{7}$ Bevægelsen hyldede ideen om domesticeret landsbylignende "townscape". Ideen om townscape udtrykker en visuel opfattelse af landskabet i kompositionelle og billedlige termer. Man er optaget af, hvorledes den urbane scenes elementer interagerer visuelt. Begrebet townscape blev introduceret i den britiske byplanlægningsdebat af Cronin Hastings, udgiver af det britiske Arcbitectural Review. Hastings agiterede for en "visual policy" i det urbane landskab, der trak på fra den engelske tradition for rural landskabsæstetik.

${ }^{8}$ Se f.eks. Phil Cohen Out of the melting pot into the fire next time - Imagining the East End as City, body, text in Imagining Cities - Scripts, signs, memory (Westwood and Williams 1997)

${ }^{9}$ Eksempelvis satte "the war of liberty" mod Pakistan i 1971 stærke rystelser gennem Londons bengalske diasfora 


\section{Litteratur}

Allinson, Ken (2006): Londons Contemporary Architecture, Oxford: Elsevier Ltd.

Bachmann-Medick, Doris (2006): Cultural Turns - Neuorientierungen in den Kulturwissenschaften, Hamburg: Rowohlts Taschenbuch Verlag.

Barker, Theo (1988): Dockland: origins and earlier history in Dockland An illustrated historical survey of life and work in east London, London: North East London Polytechnic.

Bhaba, Homi K (1994): The location of culture, London: Routledge.

Borja, Jordi and Castells, Manuel (1997): Local and Global - The Management of Cities in the Information Age, London: Earthscan Publications.

Bennett, Tony (1995): The Birth of the Museum - history, theory, politics, London: Routledge.

Crang, Mike and Thrift, Nigel (2000): Thinking Space, London: Routledge.

Conrad, Joseph (1994 [1899]): Heart of Darkness, London: Penguin Popular Classics.

Cohen, Phil (1997): Out of the melting pot into the fire next time - Imagining the East End as City, body, text in Imagining Cities - Scripts, signs, memory, London: Routledge 1997.

Döring, Jörg und Thielmann, Tristan (2008): Spatial Turn - Das Raumparadigma in den Kultur und Sozialwissenschaften, Bielefeld: Transcript Verlag.

Dockland An illustrated bistorical survey of life and work in east London, London: North East London Polytechnic.

Eade, John and Garbin, David (2002): Changing narratives of violence, struggle and resistance: Bangladeshis and the competition for resources in the global city, Oxford Development Studies, Vol. 30, No. 2.

Featherstone, Mike, Lash, Scot and Robertson, Roland (1995): Global Modernities, London: Sage Publications.

Hostettler, Eve (1988): A dockland community - the Isle of Dogs in Dockland An illustrated historical survey of life and work in east London, London: North East London Polytechnic.

Howie, Lord (1988): Dock labour history in Dockland An illustrated historical survey of life and work in east London, London: North East London Polytechnic.

Hubbard Phil, Kitchin, Rob, Bartley, Brendan \& Fuller, Duncan (2002): Thinking Geographically - Space, Theory and Contemporary Human Geography, London: Continuum.

Jacobs, Janr (1996): Edge of Empire - Postcolonialism and the city, London: Routledge

Klingmann, Anna (2007): Brandscapes - Architecture in the Experience Economy, Massachusetts: The MIT Press.

Massey, Doreen (1994): Space, Place and Gender, Minneapolis: University of Minnesota Press.

Nicholson, George (1988): "Red" sails in the sunset in Dockland An illustrated historical survey of life and work in east London, London: North East London Polytechnic.

Nielsen, Niels Kayser (2005): Steder i Europa - omstridte byer, granser og regioner, Århus: Aarhus Universitetsforlag.

Powell, Kenneth with Strongman, Cathy (2007): New London Arcbitecture 2, London: Merrel. 
Pieterses, Jan Nederveen (1995): Globalization as Hybridization in Mike Featherstone, Scott Lash and Roland Robertson Global Modernities, London: Sage Publications.

Robertson, Roland (1995): Glocalization: Time - Space and bomogeneity - Heterogeneity in Mike Featherstone, Scott Lash and Roland Robertson Global Modernities, London Sage Publications.

Sassen, Saskia (2001): The Global City New York London Tokyo, Princeton: Princeton University Press Princeton.

Said, Edward (1994): Culture and Imperialism, London: Vintage.

Said, Edward (2002): Invention, Landscape and Place in Landscape and Power, Chicago: University of Chicago Press.

Schneer, Jonathan (2006): The Thames - Englands River, London: Abacus.

Short, John Rennie (2006): Urban Theory - A Critical Assessment, London:

Palgrave Macmillan.

Soja, Edward W. (1989): Postmodern Geographies - The Reassertion of Space in Critical Social Theory, New York: Verso.

Sudjic, Deyan (2004): A Tale of Two Cities: between Forster and Adjay, Av Monografia Monographs Británicos Vol. 107.

Tomlinson; John (1999): Globalization and Culture, Cambridge: Polity Press.

Toulouse, Chris (1991): "Thatcherism, Class Politics, and Urban Development in London", Critical Sociology, vol. 18: 1. 